\title{
Research Article \\ On the Dynamics of an Oil Price Model
}

\author{
Teodoro Lara \\ Departamento de Física-Matemática, Universidad de Los Andes, N. U. Rafael Rangel, Trujillo, 03150 Trujillo State, Venezuela \\ Correspondence should be addressed to Teodoro Lara; tlara@ula.ve
}

Received 31 December 2013; Accepted 25 January 2014; Published 5 March 2014

Academic Editors: Z. Huang and X. Liu

Copyright (C) 2014 Teodoro Lara. This is an open access article distributed under the Creative Commons Attribution License, which permits unrestricted use, distribution, and reproduction in any medium, provided the original work is properly cited.

\begin{abstract}
We address the dynamic of an energy price model in a more general approach; to our knowledge, in previous works, different conditions are imposed on the energy price function at a particular value in order to characterize stability and unstability for real or complex eigenvalues. Nonexistence of periodic orbits is shown by means of Dulac's criterion; we also exhibit some pictures of solutions. Finally we modify this model and apply it to some particular cases in Venezuela economy.
\end{abstract}

\section{Introduction}

Energy is a kind of natural resource that can be utilized to obtain power by mankind. It is an important basic resource for human survival, economical development, and social progress. It plays an important role in both the social and economic development and the structure of modernization. It is also an important lever in guiding and promoting the rational development, effective utilization, and optimal allocation of energy resources [1]. In the case of crude oil it is a key commodity for global economy. As a matter of fact, it is a vital component for the economic development and growth for industrialized and developing countries in a likely manner. Moreover, political events, extreme weather, and speculation in financial market, amongst others, are major characteristics of crude oil market which increase the level of price volatility in the oil markets. The effect of oil price fluctuation extends to reach large number of goods and services which have direct impact on the economy as well as the communities. Therefore, to reduce the negative impact of the price fluctuations, it is very important to forecast the price direction. Unfortunately, fundamental variables such as oil supply, demand inventory, and gross domestic product (GDP) are not available on daily frequency which adds additional difficultly to the prediction. Some studies have indicated that the global demand will continue to rise for the long term despite the fact that oil demands from Organization for Economic Cooperative Development (OECD) countries have decreased. However, the overall demand for oil has increased and this to a large extent is due to the increasing demands of non-OECD countries, especially China.

The recent surge in the price of oil has created concern in both theory and practice. The reasons for this development can be premised on the following theoretical grounds: (i) oil price data are available at a high frequency and, therefore, there is increasing evidence of the presence of statistically significant correlations between observations that are large distance apart and (ii) in connection with the high frequency of oil price data, there is possibility of conditional heteroscedasticity, that is, time varying volatility [2-4].

Energy producers and consumers regularly attempt to forecast prices of oil, coal, and other resources over time horizons as long as twenty or thirty years. Producers make these forecasts for general purposes of strategic planning and for specific purposes of evaluating investment decisions, for example, related to resource exploration, reserve development, and production. Industrial consumers, such as petrochemical companies or electric utilities, make these forecasts for the same kinds of reasons-oil, coal, and natural gas are important input costs that can affect investment decisions (e.g., an oil- versus coal-fired power plant for an electric utility), or even the choice of products to produce (e.g., a set of chemicals or the processes used to produce those chemicals). Ideally, we would like to be able to explain energy prices in structural terms, that is, in terms of movements in supply and demand, and variables that determine supply and demand. However, structural models are not always useful for long-run forecasting, in part because it is difficult to forecast 
the explanatory variables in such models (like investment and production capacity, inventory levels, and determinants of demand) over long horizons $[2,5,6]$.

Theoretical models are based on ideals relations between factors that influence the market according to economic and financial theories. The immediate practical application of these models is usually limited, given an assumed ideal behavior, which very often does not obviate the consideration of multiple real factors that show up in practice. These models attempt to simulate the behavior of the market under ideal theoretical conditions, to try to asses, for instance, macroeconomic consequences arising from oil prices shocks, or the nature of the behavior of market factors. Most economic models of the Global Oil Market (GOM) are linear forms reduced to a single equation with some exceptions [7-11].

Nonlinear dynamics theory is introduced into energy demand-supply economic system and scores great successes in model of energy demand-supply and energy price and its analysis [12-16]. Based on the researches above, the main question is that net import has not been taken into account in the study of the energy price changes.

In this paper we address the local and global dynamic of a model considered in $[1,14,15]$, described by a new differential equation of energy price in a region of China (Jiangsu province) with huge consumption but with a little production so its energy mostly comes from import. We consider the possible existence of periodic orbits and different types of bifurcations and the interpretation of this dynamics in terms of the model under consideration.

\section{Model Formulation}

The model we consider is established and investigated in $[1,14,15]$; however we consider a more detailed analysis and formulate it for a more general function of energy price. Let us denote by $S(t), D(t), I(t), P(t)$, and $Q(t)$ quantity supplied of energy, quantity demanded of energy, net quantity of energy (import minus export, denoted by $M$ and $X$, resp.), energy price, and quantity stocked of energy (neglecting net import), respectively, at $t \geq 0$. It is important to point out that even when we mention energy instead of oil, the model works in the same way for different types of energy like gas, electricity, oil, and so on. Seeking for simplicity we drop the variable $t$ in foregoing functions, and we will use it again only if necessary. As in [1], the rising of price $d P / d t$ is assumed proportional to the gap between quantity stocked $Q$ and the determined quantity stocked $\bar{Q}$ plus net quantity imported; that is,

$$
\frac{d P}{d t}=u[\bar{Q}-Q]+r I=u[\bar{Q}-Q]+r[M-X]
$$

where $u>0, r>0$ are constants and their size determines adjustment velocity of energy price.

Remark 1. No import $(M=0)$ means that we only have export $X$, so $r[M-X]<0$ and $\bar{Q}, Q$ depend only on production, but then if $\bar{Q}-Q<0$, there is $Q-\bar{Q}$ for export.
Remark 2. In case of no import and taking into account foregoing remark, the model given in (1) now becomes

$$
\frac{d P}{d t}=u[\bar{Q}-Q]+r[Q-\bar{Q}]=(u-r)[\bar{Q}-Q] .
$$

In the same token, $Q$ is equivalent to initial energy stock $Q_{0}$ plus total volume of gap between current energy supply and energy demand, so

$$
Q(t)=Q_{0}+\int_{0}^{t}[S(s)-D(s)] d s .
$$

When energy does not surpass the threshold that purchasing power can bear, energy demand stimulates increasing of energy prices and energy prices are positively correlated with energy demand; when the increasing prices surpass the threshold, purchasing power may decrease with the increasing energy prices; in other words,

$$
D=D_{0}-\beta P-\psi(P) \frac{d P}{d t},
$$

where $D_{0}>0$ may be considered as initial demand, $\beta>0$ is the so-called marginal energy demand quantity, and $\psi(P)$ is known as function of energy price; its size reflects the dependence of energy demand on the increase rate of energy price and will be assumed to be $\psi(P) \geq 0$. Energy supply is energy quantity that energy producing enterprize is willing to sell and can be sold under the given energy price level; indeed

$$
S=S_{0}+\alpha P
$$

with $S \geq 0, \alpha>0$; $\alpha$ means marginal energy supply quantity [12]. Finally, energy net import quantity $I$ is assumed as

$$
I=n-m P, \quad n>0, m>0 .
$$

From $[1,14,15]$ the following nonlinear second-order differential equation comes out:

$$
\frac{d^{2} P}{d t^{2}}=-u(\alpha+\beta) P-[u(\psi(P))+r m] \frac{d P}{d t}+u\left(D_{0}-S_{0}\right)
$$

with $u \geq 0, r>0$ being constant and representing adjustment velocity of energy prices; $S_{0} \geq 0$ may be assumed as initially supplied quantity of energy, $\alpha>0$ is marginal energy supply quantity, and $m>0$ is a constant that shows up when $I$ is assumed as a linear function of $P[1]$.

Remark 3. In [1] function of price which is given as $\psi(P)=$ $b P+c$ with $b, c$ being real numbers, here we consider a general $\psi(P)$ and impose some conditions on it shortly.

If we call $x=P$ and $y=d P / d t$, then (7) becomes

$$
\frac{d x}{d t}=y
$$

$$
\frac{d y}{d t}=-u(\alpha+\beta) x-[u(\psi(x))+r m] y+u\left(D_{0}-S_{0}\right) .
$$


It is easy to show that the only critical point of $(8)$ is given as $\left(x_{0}, y_{0}\right)=\left(\left(D_{0}-S_{0}\right) /(\alpha+\beta), 0\right)$, so the condition $D_{0}-S_{0}>0$ is a must in order for the model to make sense (price has to be positive) [1]. Now we perform the following transformation of coordinates, $\bar{x}=x-x_{0}, \bar{y}=y$, and use that $\left(x_{0}, y_{0}\right)$ is critical point, so (8) looks like

$$
\begin{gathered}
\frac{d \bar{x}}{d t}=\bar{y} \\
\frac{d \bar{y}}{d t}=-u(\alpha+\beta) \bar{x}-\left[u\left(\psi\left(\bar{x}+x_{0}\right)\right)+r m\right] \bar{y} .
\end{gathered}
$$

Omitting bars,

$$
\begin{gathered}
\frac{d x}{d t}=y \\
\frac{d y}{d t}=-u(\alpha+\beta) x-\left[u\left(\psi\left(x+x_{0}\right)\right)+r m\right] y .
\end{gathered}
$$

Notice that (10) has the origin as unique critical point.

\section{Stability}

We study local and global stability of (10) at the origin and begin by showing no existence of periodic orbits in

$$
\Omega=\left\{(x, y) \in \mathbb{R}^{2}: 0<x<\infty, 0<y<\infty\right\}
$$

by means of Dulac's criterion $[17,18]$.

Lemma 4. System (8) has no periodic orbits in $\Omega$.

Proof. Let $G$ be defined as $G(x, y)=x^{3} / y$ and

$$
\begin{aligned}
f_{1}(x, y) & =y, f_{2}(x, y) \\
& =-u(\alpha+\beta) x-\left[u\left(\psi\left(x+x_{0}\right)\right)+r m\right] y .
\end{aligned}
$$

Then

$$
\begin{aligned}
& \frac{\partial\left(G f_{1}\right)}{\partial x}+\frac{\partial\left(G f_{2}\right)}{\partial y}=\frac{x^{2}}{y^{2}}\left[3 y^{2}+u(\alpha+\beta) x^{2}\right]>0, \\
& \text { for }(x, y) \in \Omega \text {. }
\end{aligned}
$$

The conclusion now follows from Dulac's criterion.

In order to calculate Jacobian for (8) at the origin we assume that $\psi$ is differentiable at $x_{0}=D_{0}-S_{0}$; then it is given by

$$
A=\left[\begin{array}{cc}
0 & 1 \\
-u(\alpha+\beta) & -u \psi\left(x_{0}\right)-r m
\end{array}\right] .
$$

Consequently, each eigenvalue $\lambda$ associated with $A$ satisfies the equation

$$
\lambda^{2}+\left(u \psi\left(x_{0}\right)+r m\right) \lambda+u(\alpha+\beta)=0 .
$$

Roots of foregoing equation are given as

$$
\begin{array}{r}
\lambda_{1,2}=\frac{-B \pm \sqrt{B^{2}-4 C}}{2}, \\
B=u \psi\left(x_{0}\right)+r m, \quad C=u(\alpha+\beta) .
\end{array}
$$

We always may assume $u>0$ because otherwise eigenvalues of $A$ are $\lambda_{1}=0, \lambda_{2}=-r m<0$, and in this case a saddle node bifurcation shows up.

Remark 5. It is clear that $\operatorname{det}(A)=u(\alpha+\beta)$ and $\operatorname{tr}(A)=$ $-u \psi\left(x_{0}\right)-r m$; however we are going to characterize $\lambda_{1,2}$ in terms of $\psi\left(x_{0}\right)$, depending on the sign of $\Delta=B^{2}-4 C$.

It is easy to verify that

$$
\Delta=u^{2} \psi\left(x_{0}\right)^{2}+2\left[\psi\left(x_{0}\right) r m-2(\alpha+\beta)\right] u+r^{2} m^{2} .
$$

Theorem 6. If $\psi\left(x_{0}\right)=0$, then

(1) $\Delta=0$ if and only if $u=r^{2} m^{2} / 4(\alpha+\beta)$, which means $\lambda_{1}=\lambda_{2}=-r m / 2<0$;

(2) $\Delta>0$ if and only if $0 \leq u<r^{2} m^{2} / 4(\alpha+\beta)$, that is, two real and different roots which are both positive;

(3) $\Delta<0$ if and only if $u>r^{2} m^{2} / 4(\alpha+\beta)$, or complex conjugate roots with negative real part.

Proof. If $\psi\left(x_{0}\right)=0$, then $\operatorname{tr}(A)=r m>0$ and $\operatorname{det}(A)=u(\alpha+$ $\beta)>0$ and, from (17), $\Delta=-4(\alpha+\beta) u+r^{2} m^{2}$, where $\operatorname{tr}(A)$ stands for trace of $A$; therefore

(1) $\Delta=0$ if and only if $-4(\alpha+\beta) u+r^{2} m^{2}=0$;

(2) $\Delta>0$ is equivalent to $-4(\alpha+\beta) u+r^{2} m^{2}>0$ and in a similar fashion when $\Delta<0$.

Remark 7. The number $r^{2} m^{2} / 4(\alpha+\beta)$ is a threshold value for the above case.

The following result gives a characterization of eigenvalues of $A$ in terms of $\psi\left(x_{0}\right)$.

Theorem 8. If $\psi\left(x_{0}\right) \neq 0$, then the following statements take place.

(1) $\Delta=0$ if and only if $\left(1-2(\alpha+\beta) / \psi\left(x_{0}\right)\right)^{2}=$ $\left[\psi\left(x_{0}\right)\right]^{2}\left[\left(u \psi\left(x_{0}\right)+\psi\left(x_{0}-2(\alpha+\beta)\right) / \psi\left(x_{0}\right)\right)^{2}+r^{2} m^{2}\right] ;$ that is, $\lambda_{1}=\lambda_{2}=-\left(u \psi\left(x_{0}\right)+r m\right) / 2<0$.

(2) $\Delta>0$ if and only if $\left(1-2(\alpha+\beta) / \psi\left(x_{0}\right)\right)^{2}<$ $\left[\psi\left(x_{0}\right)\right]^{2}\left[\left(u \psi\left(x_{0}\right)+\psi\left(x_{0}-2(\alpha+\beta)\right) / \psi\left(x_{0}\right)\right)^{2}+r^{2} m^{2}\right] ;$ here $\lambda_{1,2}$ are different but negative.

(3) $\Delta<0$ if and only if $\left(1-2(\alpha+\beta) / \psi\left(x_{0}\right)\right)^{2}>$ $\left[\psi\left(x_{0}\right)\right]^{2}\left[\left(u \psi\left(x_{0}\right)+\psi\left(x_{0}-2(\alpha+\beta)\right) / \psi\left(x_{0}\right)\right)^{2}+r^{2} m^{2}\right] ;$ that is, $\lambda_{1,2}$ are complex conjugate with negative real part. 
Proof. $\Delta$ can be written as

$$
\begin{aligned}
\Delta= & {\left[u \psi\left(x_{0}\right)+\frac{\psi\left(x_{0}-2(\alpha+\beta)\right)}{\psi\left(x_{0}\right)}\right]^{2} } \\
& +r^{2} m^{2}-\left[\frac{\psi\left(x_{0}-2(\alpha+\beta)\right)}{\psi\left(x_{0}\right)}\right]^{2},
\end{aligned}
$$

and $\operatorname{tr}(A)=-u \psi\left(x_{0}\right)-r m$ and $\operatorname{det}(A)=u(\alpha+\beta)>0$.

Stability now can be summarized, from the above results, in the following.

Corollary 9. Equilibrium of system (8) is

(1) locally asymptotically stable (stable node) if
(a) $\psi\left(x_{0}\right)=0$ and $\Delta=0$,
(b) $\psi\left(x_{0}\right) \neq 0, \Delta=0$, or
(c) $\psi\left(x_{0}\right) \neq 0, \Delta>0$;

(2) unstable (unstable node) if $\psi\left(x_{0}\right)=0$ and $\Delta>0$;

(3) stable focus if
(a) $\psi a\left(x_{0}\right)=0$ and $\Delta<0$ or
(b) $\psi\left(x_{0}\right) \neq 0$ and $\Delta<0$.

Now by means of Lemma 4 and first part of foregoing corollary we have the following.

Theorem 10. Local stability of system (8) is global.

It is worth mentioning here that price function $\psi$ at $x_{0}$ plays a key role in studying stability properties of critical point as previous results show.

Example 11. We realize that a simple curve like affine function is not the best approximation to the price function; instead we may consider quadratic or cubic ones in order to get an improved approximation. In the next two examples a quadratic and cubic expression for $\psi$ and conditions for real roots at initial $x_{0}$ are given.

(1) Let us consider $\psi(x)=a x^{2}+b x+c$, with $a \neq 0 ; \psi\left(x_{0}\right)=$ 0 implies real roots if $b^{2} \geq 4 a$ and complex ones in case $b^{2}<4 a$.

(2) If now $\psi(x)=a x^{3}+b x^{2}+c x+d$, with $a \neq 0$, in this case we will have one or three real roots.

\section{Some Numerical}

Next we perform some numerical implementation in order to show pictures of trajectories for particular functions like the ones given in previous example (Figures 1, 2, and 3).

It is important to point out that we have chosen cubic and quadratic expressions for $\psi$; our numerical analysis shows no presence of periodic orbits which is something we know from the previous analysis.

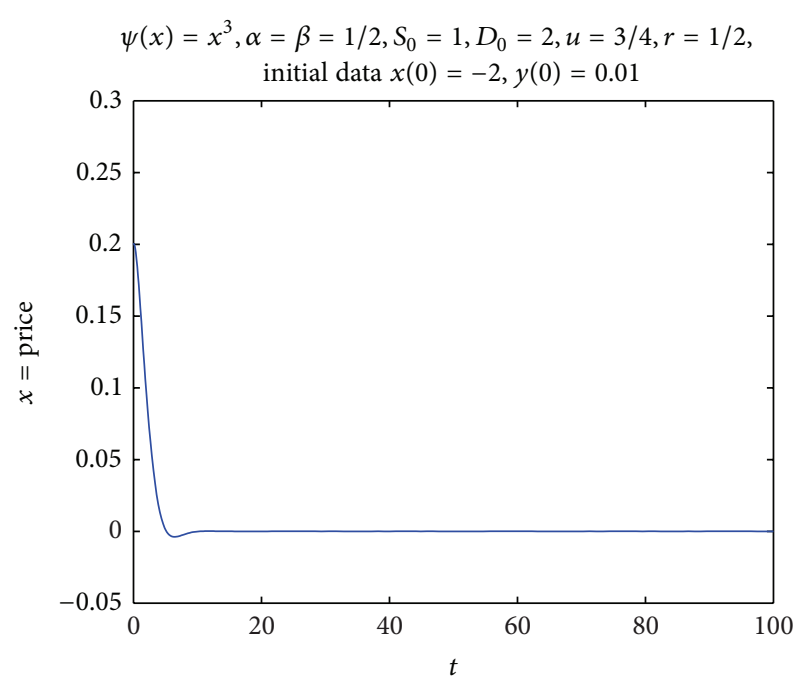

Figure 1: A cubic and picture of price.

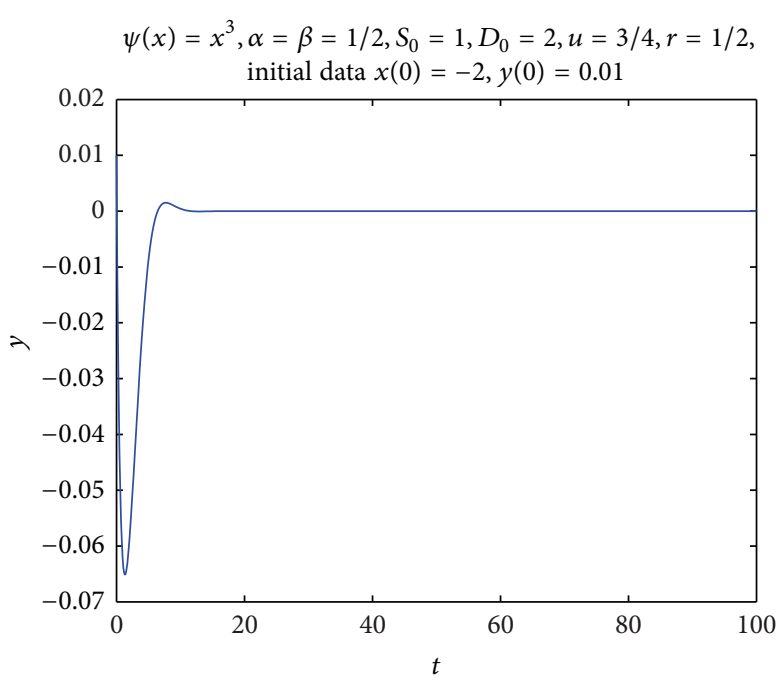

FIgURE 2: A cubic and picture for speed of price.

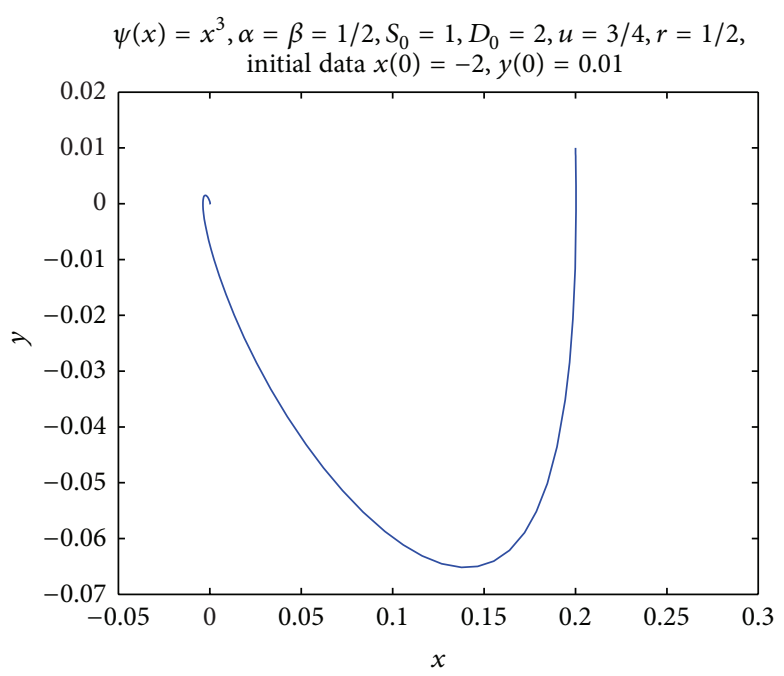

FIgURe 3: A cubic and orbits. 


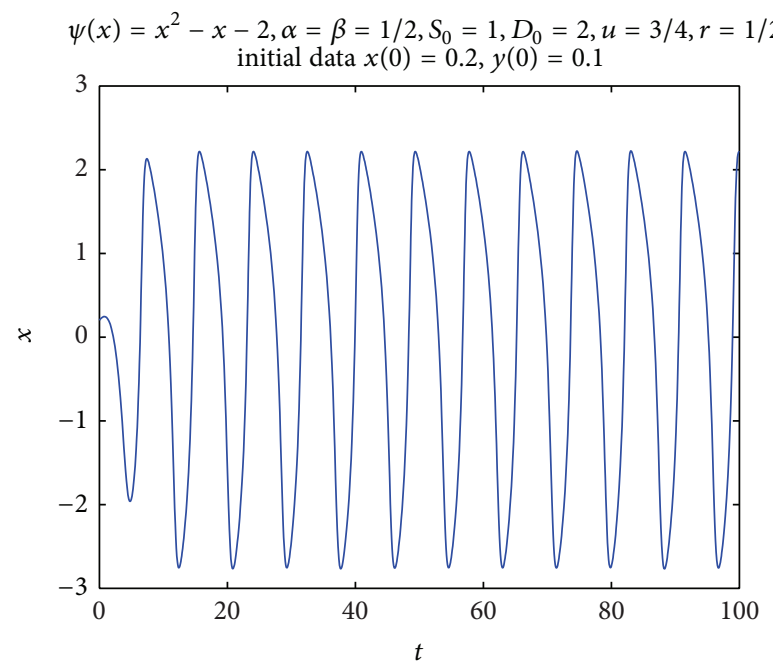

FIGURE 4: A quadratic being null at some point and picture of price.

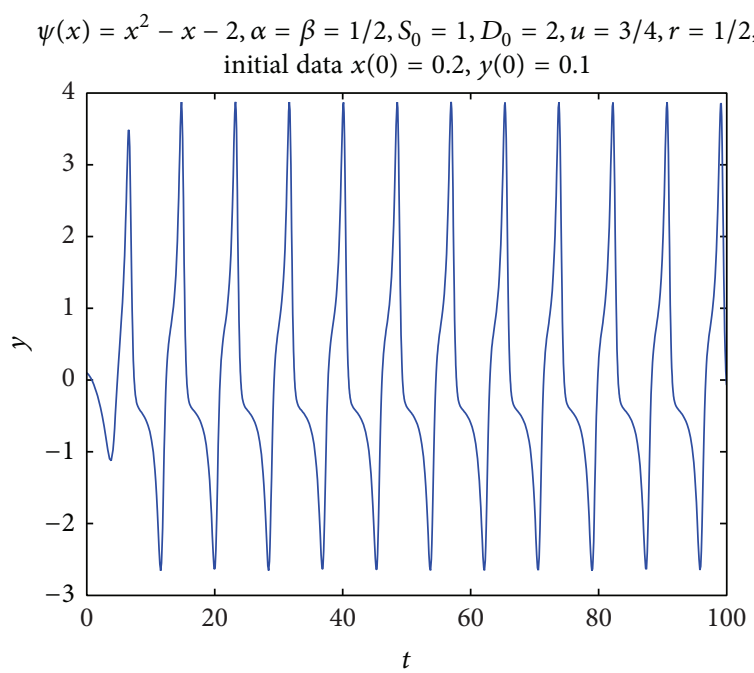

FIGURE 5: A quadratic being null at some point and picture of speed of price.

Figures 4, 5, and 6 are included only to demonstrate that, in the case when $\psi$ may be zero at some point, the result is no realist since a kind of attractor may show up (Figure 6), and that is impossible to happen.

Finally we would like to state that for other types of $\psi$ like $\psi(x)=1 / x$ and $\psi(x)=x^{2}+x+1$ the general behavior is similar to the case shown in Figures 4, 5 and 6.

\section{An Application to Local Economy}

In a country like Venezuela where most of cereals, grains, and vegetables which constitute important part of Venezuelan diet are grown in its fields and do not need to be imported, so the country stands up on local production, the model we have studied can be reformulated in order to describe variations of

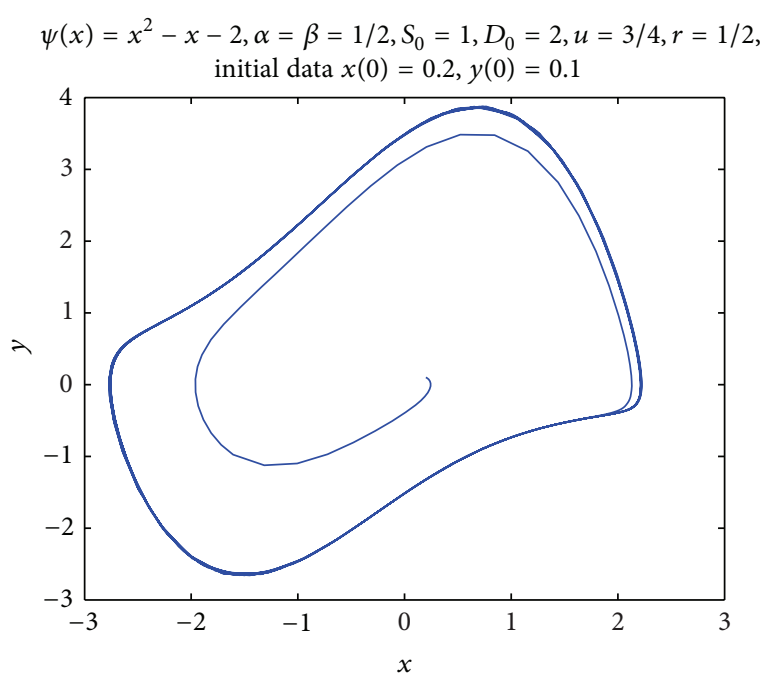

FIGURE 6: A quadratic being null at some point and orbits.

price of this particular items as we show shortly. According to Remark 2, the model with no import now looks like

$$
\frac{d P}{d t}=(u-r)[\bar{Q}-Q]
$$

where $Q$ is quantity stocked of item and is given by (3), $\bar{Q}$ is quantity needed to satisfy local necessities of consumption (country needs), $u>0, r>0$ are constants, and their size determines adjustment velocity of item price. We use the word "item" to indicate one of the above mentioned, that is, cereals, grains or vegetables.

In this context some words need to be said; $S$ and $D$ are quantity supplied and quantity demanded of item, respectively, and given by (4) and (5) and $P$ is the price. At the same time, $\psi(P)$, the function of item price reflects the dependence of item demand on the increase rate of item price and will be assumed to be $\psi(P) \geq 0$.

From (19) we may derive the new system describing variation of prices of item; actually

$$
\begin{aligned}
\frac{d^{2} P}{d t^{2}} & =-(u-r)[S-D] \\
& =-(u-r)\left[S_{0}+\alpha P-D_{0}+\beta P+\psi(P) \frac{d P}{d t}\right],
\end{aligned}
$$

where $D_{0}$ and $S_{0}$ are quantity demanded of item and quantity supplied of item at time $t=0$, respectively. Foregoing equation, as done previously, can be written by taking $x=P$, $y=d P / d t$ and performing transformation of coordinates similar to (10), as

$$
\frac{d x}{d t}=y
$$

$$
\frac{d y}{d t}=-(u-r)\left[(\alpha+\beta) x+\psi\left(x+x_{0}\right) y\right] \text {, }
$$


and as before $x_{0}=\left(S_{0}-D_{0}\right) /(\alpha+\beta)$. The only critical point is $(0,0)$ with Jacobian matrix given by

$$
A=J(0,0)=\left[\begin{array}{cc}
0 & 1 \\
-(u-r) & \psi\left(x_{0}\right)
\end{array}\right],
$$

and therefore $\operatorname{det}(A)=u-r$ and $\operatorname{tr}(A)=\psi\left(x_{0}\right)$.

Stability of this system now is easy to determine by using expressions for $\operatorname{det}(A)$ and $\operatorname{tr}(A)$ given above and we have the following.

Proposition 12. If $\lambda_{1}, \lambda_{2}$ are eigenvalues of $A$, then

(1) if $u>r$ and $\psi\left(x_{0}\right)>0$, then $\lambda_{1}>0, \lambda_{2}>0$, and origin is unstable;

(2) if $u<r$ and $\psi\left(x_{0}\right) \geq 0$, then $\lambda_{1}<0<\lambda_{2}$ or $\lambda_{2}<0<$ $\lambda_{2}$ and origin is a saddle;

(3) if $u=r$, then at $(0,0)$ there is a saddle-node bifurcation.

It is worth making some comments at this time; first of all we point out that the value $u=r$ is a threshold; on the other hand at this point price $P$ is constant and so are $S$ and $D$, the quantity supplied and quantity demanded of item. Meanwhile, by Remark 1 , we have that $\bar{Q}-Q<0$; then $u>r$ means $d P / d t<0$ which is equivalent to saying that price is decreasing while $u<r$ means $d P / d t>0$ and price is increasing. This shows again the relevance of value $u=r$.

\section{Conflict of Interests}

The author declares that there is no conflict of interests regarding the publication of this paper.

\section{Acknowledgment}

This research has been partially supported by Central Bank of Venezuela.

\section{References}

[1] X. G. Tao, L. X. Tian, and M. Fu, "A novel differential equation of energy price: the case of jiangsu province," International Journal of Nonlinear Sciences, vol. 13, pp. 248-251, 2012.

[2] H. Askari and N. Krichene, "Oil price dynamics," Energy Economics, vol. 30, no. 5, pp. 2134-2153, 2008.

[3] R. Harris and R. Sollis, Applied Time Series Modelling and Forecasting, John Wiley and Sons, London, UK, 2nd edition, 2005.

[4] A. A. Salisu and I. O. Fasanya, "Comparative performance of volatility models for oil price," International Journal of Energy Economics and Policy, vol. 2, pp. 167-183, 2012.

[5] J. Y. Campbell, W. Andrew Lo, and A. C. MacKinlay, The Econometrics of Financial Markets, Princeton University Press, Princeton, NJ, USA, 1997.

[6] R. S. Pindyck, "Inventories and the short-run dynamics of commodity prices," The RAND Journal of Economics, vol. 25, pp. 141-159, 1994.

[7] A. Campolmi, "Oil Price Shocks: Demand vs Supply in two country model,” MNB Working Papers 5, 2008.
[8] S. Dées, P. Karadeloglou, R. K. Kaufmann, and M. Sánchez, "Modelling the world oil market: assessment of a quarterly econometric model," Energy Policy, vol. 35, no. 1, pp. 178-191, 2007.

[9] C. Y. Lin, "Lin estimating and testing a dynamic model of OPEC and non-OPEC", Research Report UCD-ITS-RR-0728, Instite of Transportation Studies, University of Califirnia, Rickey Davis, Ala, USA, 2008.

[10] M. F. Lopez, S. L. Carciente, J. Contreras, and P. C. Paiva, "Behavior of the global oil market (1995-2008) as described by a system dynamics model," Análise Econômica Do Direito, vol. 29, no. 56, pp. 7-34, 2011.

[11] S. Moshiri and F. Foroutan, "Forecasting nonlinear crude oil futures prices," Energy Journal, vol. 27, no. 4, pp. 81-95, 2006.

[12] X. Z. Deng, L. X. Tian, and X. B. Duan, "Dynamical model for energy price and its analysiz," Statistics and Policy, vol. 2, 10 pages, 2007.

[13] M. Sun, L. Tian, S. Jiang, and J. Xu, "Feedback control and adaptive control of the energy resource chaotic system," Chaos, Solitons and Fractals, vol. 32, no. 5, pp. 1725-1734, 2007.

[14] M. Sun, L. Tian, and Y. Fu, "An energy resources demand-supply system and its dynamical analysis," Chaos, Solitons and Fractals, vol. 32, no. 1, pp. 168-180, 2007.

[15] M. Sun, L. Tian, Y. Fu, and W. Qian, "Dynamics and adaptive synchronization of the energy resource system," Chaos, Solitons and Fractals, vol. 31, no. 4, pp. 879-888, 2007.

[16] L. Tian and H. Qian, “Time delayed differential equation model and its dynamic analysis for energy price," Journal of Jiangsu University, vol. 31, no. 2, pp. 240-244, 2010.

[17] J. Guckenheimer and P. Holmes, Nonlinear Oscillations, Dynamical Systems and Bifurcations of Vector Fields, Springer, New York, NY, USA, 1993.

[18] L. Perko, Differential Equations and Dynamical Systems, Springer, New York, NY, USA, 3rd edition, 1996. 


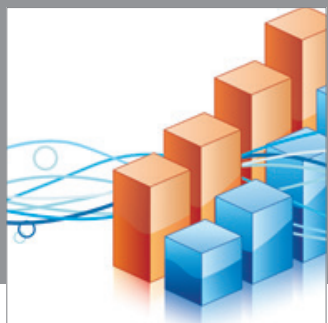

Advances in

Operations Research

mansans

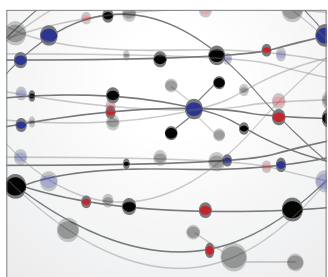

The Scientific World Journal
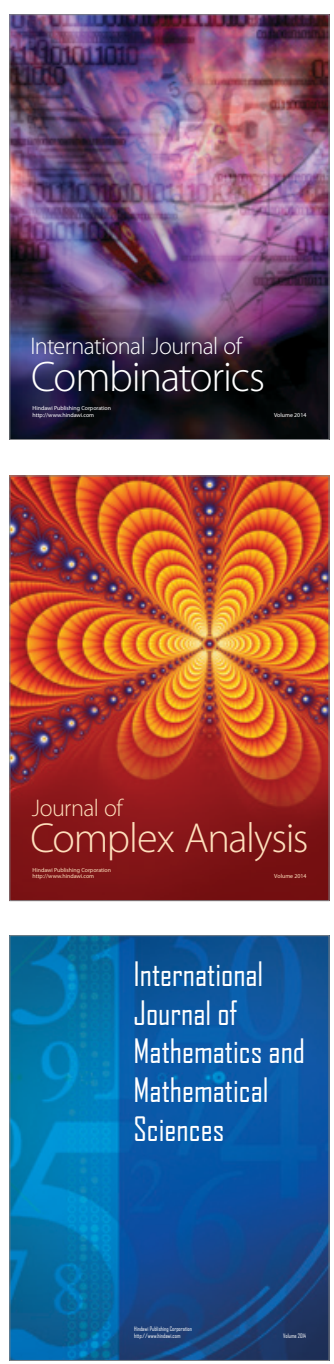
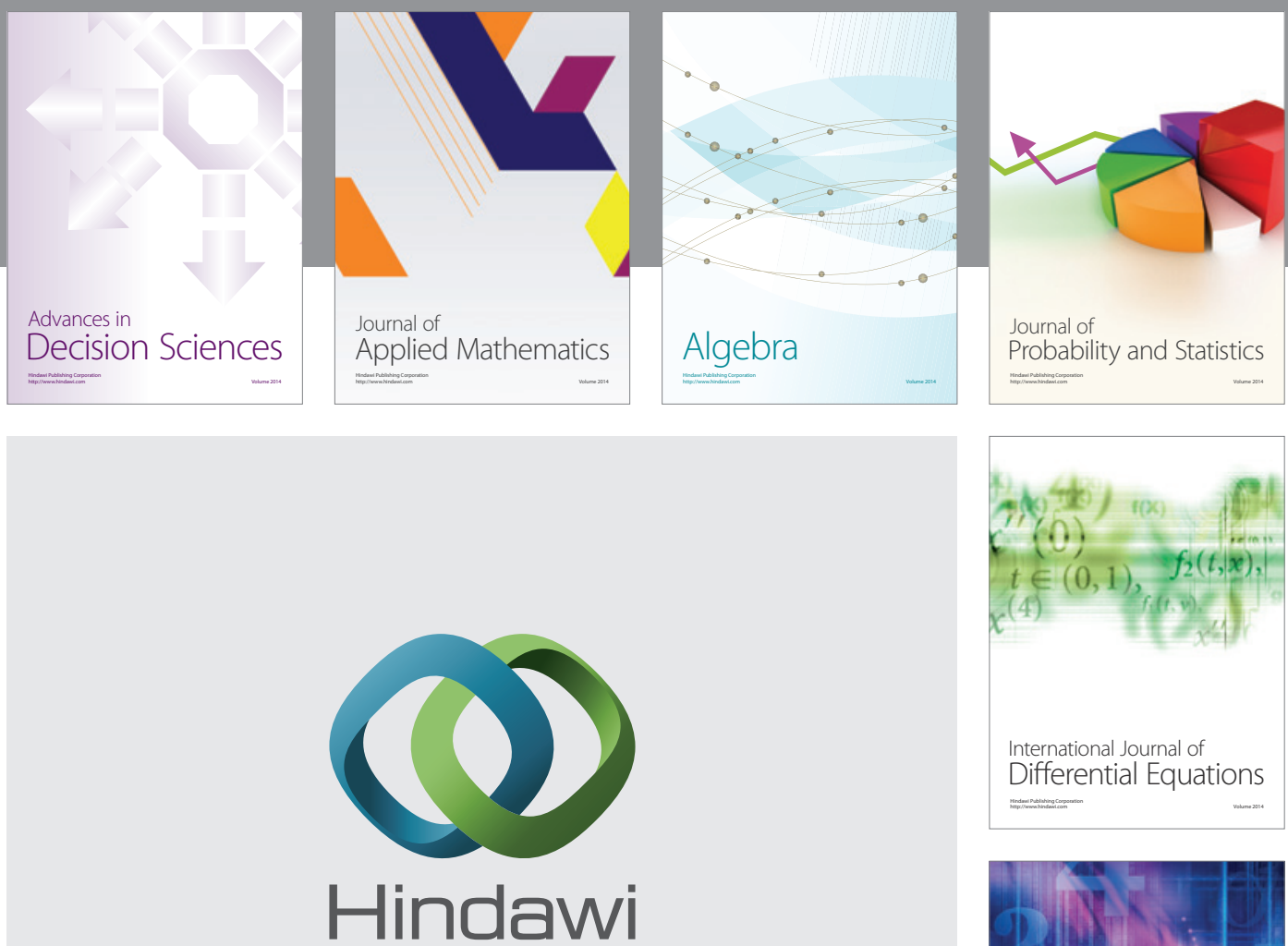

Submit your manuscripts at http://www.hindawi.com
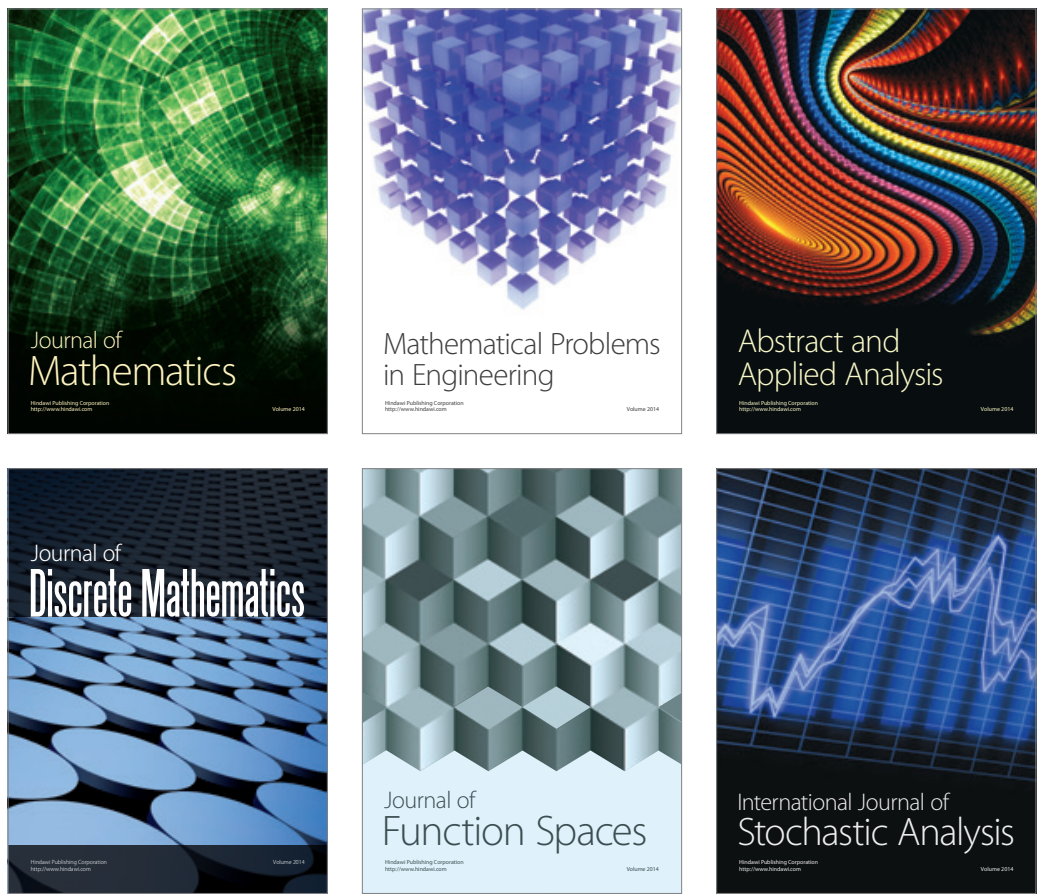

Journal of

Function Spaces

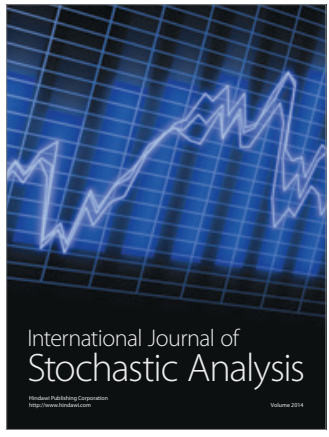

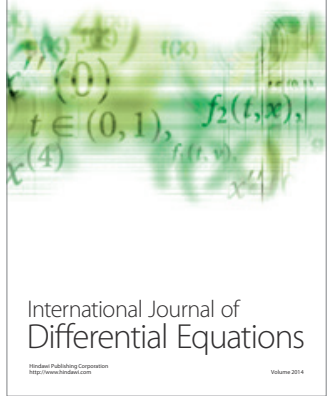
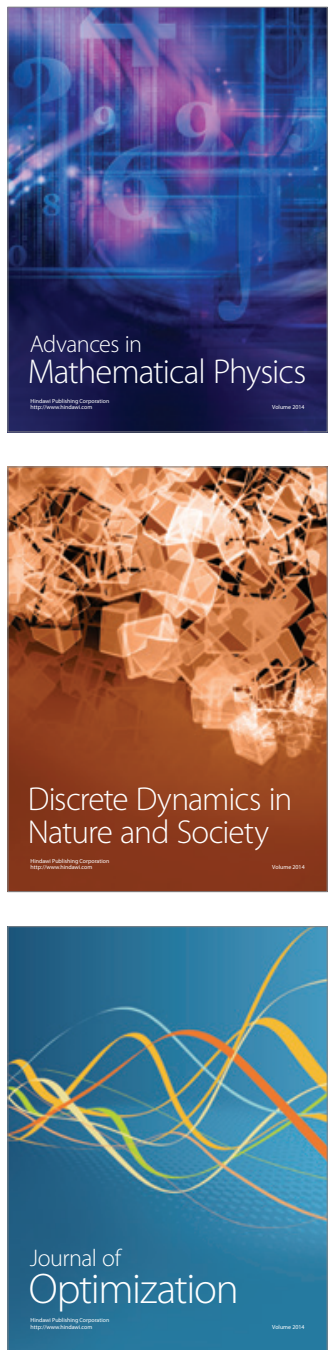